\title{
Assessments of urban aerosol pollution in Moscow and its radiative effects
}

\author{
N. Y. Chubarova ${ }^{1}$, M. A. Sviridenkov ${ }^{2}$, A. Smirnov ${ }^{3}$, and B. N. Holben ${ }^{3}$ \\ ${ }^{1}$ Faculty of Geography, Moscow State University, Moscow, Russia \\ ${ }^{2}$ A. M. Obukhov Institute of Atmospheric Physics RAS, Moscow, Russia \\ ${ }^{3}$ NASA Goddard Space Flight Center, code 614.4, Greenbelt, MD 20771, USA
}

Received: 1 November 2010 - Published in Atmos. Meas. Tech. Discuss.: 3 December 2010

Revised: 17 February 2011 - Accepted: 18 February 2011 - Published: 28 February 2011

\begin{abstract}
Simultaneous measurements by the collocated AERONET CIMEL sun/sky photometers at the Moscow State University Meteorological Observatory (MSU MO) and at the Zvenigorod Scientific Station (ZSS) of the A. M. Obukhov Institute of Atmospheric Physics during September 2006-April 2009 provide the estimates of the effects of urban pollution on various aerosol properties in different seasons. The average difference in aerosol optical thickness between MO MSU and ZSS, which can characterize the effect of aerosol pollution, has been estimated to be about $d \mathrm{AOT}=0.02$ in visible spectral region. The most pronounced difference is observed in winter conditions when relative AOT difference can reach $26 \%$. The high correlation of the AOT's, the Angstrom exponent values and the effective radii between the sites confirms that natural processes are the dominating factor in the changes of the aerosol properties even over the Moscow megacity area. The existence of positive correlation between dAOT and difference in water vapor content explains many cases with large $d$ AOT between the sites by the time lag in the airmass advection. However, after excluding the difference due to this factor, AOT in Moscow remains higher even in a larger number of cases (more than $75 \%$ ) with the same mean $d \mathrm{AOT}=0.02$. Due to the negative average difference in aerosol radiative forcing at the TOA of about $d \mathrm{ARF}_{\mathrm{TOA}}=-0.9 \mathrm{~W} \mathrm{~m}^{-2}$, the aerosol urban pollution provides a distinct cooling effect of the atmosphere. The PAR and UV irradiance reaching the ground is only $2-3 \%$ lower in Moscow due to the pollution effects, though in some situations the attenuation can reach $13 \%$ in visible and more than $20 \%$ in UV spectral region.
\end{abstract}

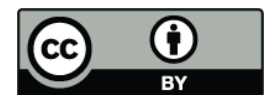

Correspondence to: N. Y. Chubarova (chubarova@imp.kiae.ru)

\section{Introduction}

The urban pollution causes a significant effect on the aerosol properties in the troposphere. This, in turn can provide a notable feedback on the climate change via changes in radiative forcing (IPCC, 2007). However, estimating urban polluted aerosol properties and distinguishing them from the typical background aerosol conditions is still an open problem.

This can be done using satellite remote sensing technique via different satellite instruments (i.e. AVHRR, OMI, MODIS, CERES, AATSR, MERIS, GLAS, SeaWiFs, MISR), but the accuracy of satellite methods for most aerosol characteristics is still not very high.

Ground-based measurements are the most accurate and low-cost tools for studying these effects. Some attempts to distinguish the properties of urban aerosols were previously done (Gorbarenko, 1997; Eck et al., 1999; Dubovik et al., 2002). For example, in Gorbarenko (1997) a significant influence of Moscow city on AOT at $550 \mathrm{~nm}$ was estimated as twice as high than the background values in some years in 1980s. However, the evaluated AOT values were obtained not by the direct measurements but by using the Tarasova and Yarkho method (1991) from the measurements of the direct shortwave irradiance and water vapor content. Since that time there was a significant change in fuel from coal to gas in the middle of 1980s throughout the whole Europe, including Russia, which may result in reducing loading of sulphate aerosols, that is confirmed by the observed pronounced negative AOT trends (Ruckstuhl et al., 2008; Kazadzis et al., 2007; Gorbarenko et al., 2006).

One of the most widespread ground-based aerosol networks is the Aerosol Robotic Network - AERONET (http: //aeronet.gsfc.nasa.gov/) (Holben et al., 1998), which has been in operation since the middle of 1990s. Accurate multi-channel measurements by CIMEL sun/sky photometer through UV to near-infrared spectral region provide the

Published by Copernicus Publications on behalf of the European Geosciences Union. 
data for evaluating a spectral dependence of aerosol optical thickness as well as many other inversion products including single scattering albedo and asymmetry factor of the aerosol phase function (Dubovik and King, 2000). By using the AERONET data, some attempts were made to characterize the properties of different kinds of aerosol including urban/industrial type (Eck et al., 1999; Dubovik et al., 2002). The results showed the significant differences in urban aerosol properties in different regions of the world. However, the analysis was done just for separate sites and the joint influence of urban pollution and natural background aerosol conditions can result in this difference.

In this study we used high quality AERONET data from the two sites located in Moscow at the Moscow State University and at Zvenigorod, the nearby clean area. The application of simultaneously measured different aerosol characteristics allows us to calculating the city impact on aerosol pollution and to evaluating its influence on radiative properties of the atmosphere.

\section{Data and methods of the analysis}

The analysis has been fulfilled on the base of simultaneous measurements by AERONET CIMEL sun/sky photometers located at the Moscow State University Meteorological Observatory (MSU MO) $\left(55.7^{\circ} \mathrm{N}, 37.5^{\circ} \mathrm{E}\right)$ and at the Zvenigorod Scientific Station (ZSS) of the A. M. Obukhov Institute of Atmospheric Physics (55.7 $\mathrm{N}, 36.8^{\circ} \mathrm{E}$ ). The distance between the sites is about $55 \mathrm{~km}$, the time shift between measurements is only $3 \mathrm{~min}$. Since westerly wind direction prevails over European Russia, we can consider the ZSS as the site located upwind to the Moscow pollution area, and, hence, it can be regarded as a site with the background aerosol conditions relative to Moscow megacity influence.

Direct Sun measurements are made with $1.2^{\circ}$ full field of view at 340, 380, 440, 500, 675, 870, 940 and $1020 \mathrm{~nm}$ every $15 \mathrm{~min}$ during daytime (Holben et al., 1998). These measurements are used to compute aerosol optical thickness except that for $940 \mathrm{~nm}$ channel, which is used to estimate the total water content $W$. The uncertainty of AOT measurements does not exceed 0.01 in visible range and 0.02 in UV spectral range (Eck et al., 1999) for field instruments. Direct Sun measurements also provide the data for estimating the Angstrom exponent from spectral values of AOT by the least square method. The sky radiance measurements at $440,675,870$, and $1020 \mathrm{~nm}$ in conjunction with the direct Sun measurements are used to retrieve different microphysical, optical and raditive aerosol characteristics (Dubovik and King, 2000). The accuracy of individual aerosol retrievals is analyzed in (Dubovik et al., 2000, 2002). It was shown there that for high aerosol loading (AOT440 $>0.4$ ), the retrievals of the single scattering albedo have the uncertainty of about 0.03 while at AOT at $440 \mathrm{~nm}$ less than 0.2 the accuracy level drops down to $0.05-0.07$. The error in aerosol volume size distribution within the intermediate particle size range $(0.1 \mu \mathrm{m} \leq r \leq 7 \mu \mathrm{m})$ does not exceed $10 \%$ for practically all situations (Dubovik et al., 2000).

In addition, we used the MODIS (collection 5) AOT550 retrievals to characterize spatial features in AOT distribution over the Moscow area and to compare them with the results of the ground-based observations.

The CIMEL cloud-screening algorithm developed by Smirnov et al. (2000) is known to work well, except for the cases with thin and uniform high level cloudiness. Their non account can add about 0.03-0.05 to monthly mean AOT values (Uliumdzhieva et al., 2005). To remove these cases we used additional filtering due to hourly visual cloud information available at the MSU MO. This helps to remove the AOT measurements, which were contaminated by overcast high level cloudiness.

In addition, the data were hourly averaged that makes the dataset more uniform and comparable with the other AERONET retrieval results, which have one hour resolution. As a result, this dataset (Dataset 1) contains the pairs of quasi-simultaneous measurements at the Moscow and Zvenigorod sites. Total number of the hourly averaged cases is about 1200 . In order to examine the quality of the Dataset 1 we compared the monthly mean differences in AOT taken from this dataset with the differences in AOT taken directly from the AERONET website for Moscow and Zvenigorod sites. Figure 1 presents the comparison between the AOT differences obtained by the two methods: the standard AERONET method (marked as the M1 method) and the more accurate approach, which has been described above (marked as the M2 method).

One can see that the more accurate second approach (M2) provides the absence of negative monthly mean AOT differences compared with the results of the M1 method. These negative AOT differences correspond to the situations, when Moscow AOT's are smaller than those in Zvenigorod. So the absence of negative monthly mean AOT differences in M2 approach is more reasonable, since Moscow should provide some additional emission of aerosol particles. Overall, the application of the more accurate method provides the difference of \pm 0.05 with the standard approach for monthly mean AOT values.

The analysis of the differences in the retrieved aerosol parameters was made on the base of the Dataset 2. In addition to the standard quality control criteria described in (Dubovik et al., 2000) the cloud filter with NA $<5$ (where NA is a total cloud amount, in tenth) has been applied to avoid the cloud contamination mainly by uniform thin cirrus clouds. Total number of pairs is 112 after removing of additional 3 cases, which were characterized by unrealistically low single scattering albedo (SSA) values in Zvenigorod. It should be mentioned that these low SSA values were adjacent to the similar unrealistically low values, which had been removed from the Zvenigorod level 2.0 dataset at the AERONET website. 


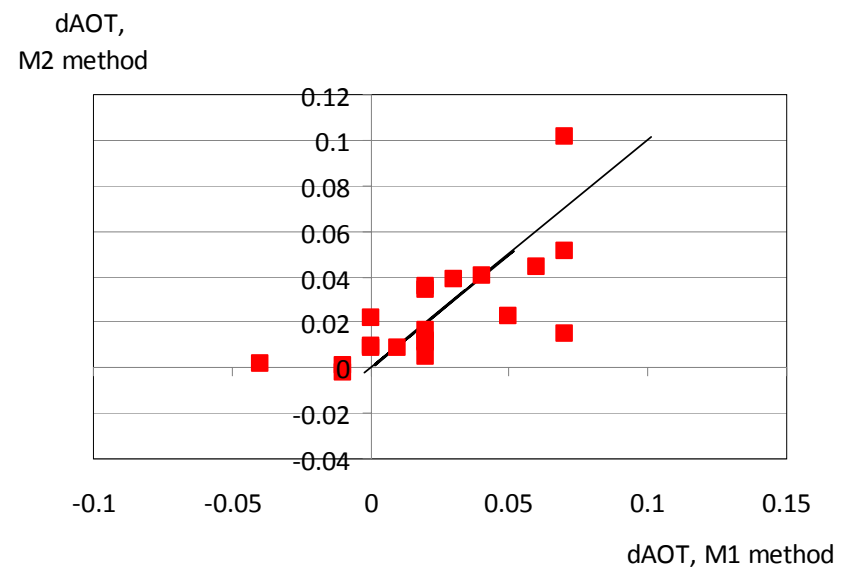

Fig. 1. Comparison between the monthly mean differences in AOT500 obtained by the standard M1 and by the proposed M2 methods. See the details in the text.

The analysis of the differences between the aerosol data at the two sites were made by the standard approach by estimating the significance of the difference of an aerosol parameter between two samples. We showed that the differences of all the parameters has passed successfully the KolmogorovSmirnov test on normal distribution (Afifi and Azen, 1979) and, hence, the standard t-Student criterion $(t s)$ can be applied for calculation of the confidence level $\delta$ for each mean value of an aerosol parameter as follows:

$\delta_{\Delta P}= \pm \frac{\left(t s \cdot \sigma_{\Delta P}\right)}{\sqrt{N-1}}$

where $\sigma_{\Delta P}$ - the standard deviation of the difference $\Delta P$ obtained between the CIMEL measurements at the two sites, $P$ is the parameter analyzed; $N$ is the number of cases. $t s=1.96$ when $N \rightarrow \infty$ at $95 \%$ significance level.

In addition, since the aerosol optical thickness is the object of the main interest, we have fulfilled additional analysis accounting for the uncertainty of measurements using the following expression:

$\delta \Delta \mathrm{AOT}=\sqrt{\left(\frac{\left(t s \cdot \sigma_{\Delta \mathrm{AOT}}\right)}{\sqrt{N-1}}\right)^{2}+\left(\delta \mathrm{AOT}_{1}\right)^{2}+\left(\delta \mathrm{AOT}_{2}\right)^{2}}$

where $\delta \mathrm{AOT}_{1}$ and $\delta \mathrm{AOT}_{2}$ are the typical systematic instrumental errors ( 0.01 in visible range) of Moscow and Zvenigorod instruments; $\sigma_{\triangle \mathrm{AOT}}$ is the standard deviation of the difference $\triangle \mathrm{AOT}$ obtained between the CIMEL measurements at the two sites.

\section{Results}

The comparison between aerosol optical thickness at $500 \mathrm{~nm}$ in Moscow and Zvenigorod for the whole period of observations is presented in Fig. 2. One can see a strong dependence between Moscow and background AOT's with correlation coefficient $r>0.9$. The lowest, though still quite high,

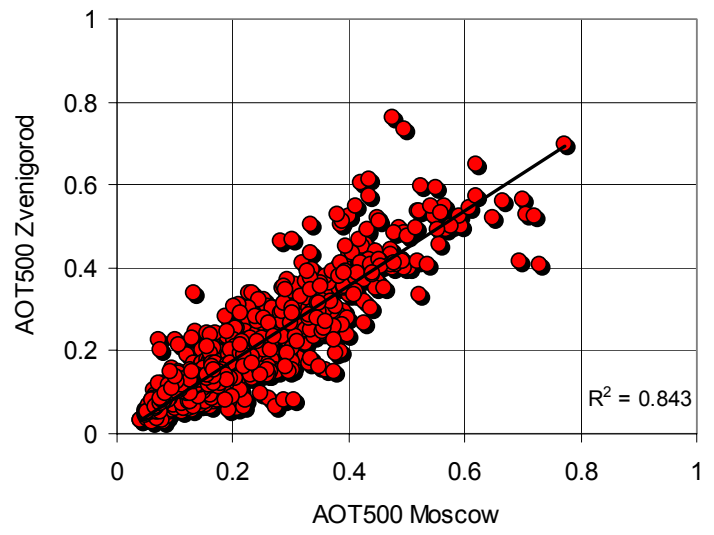

Fig. 2. Comparison between Zvenigorod and Moscow simultaneous AOT500 measurements.

correlation between the AOT's is observed in winter $(r=0.8)$. This shows the similar character of aerosol loading changes over vast areas including the megacity region in all seasons and, hence, the importance of natural air advection processes and processes of aerosol transformation on regional scale.

Table 1 shows mean aerosol characteristics in Moscow and the statistics of the differences between Moscow and Zvenigorod $\left(d P=P_{\text {Moscow }}-P_{\text {Zvenigorod }}\right)$ for various characteristics observed in different seasons. The seasonal changes in AOT in visible spectral range has a pronounced minimum in winter of about 0.1 , while in other seasons it is about 0.2 (for the detailed analysis of the AOT climatology see, for example; Chubarova, 2009). The mean overall difference in AOT is about 0.02 , which is statistically significant at the $95 \%$ level. The additional test with account for the uncertainty of AOT CIMEL measurements also shows the significance of the differences for all the seasons. The highest absolute and relative positive difference is observed during winter period and comprises, respectively, $d$ AOT500 $=0.03$ and $26 \%$. This happens in accordance with the processes of accumulation of pollutants in temperature inversion conditions, which are typical for winter season. However, the statistics is not very large for winter months due to the prevalence of overcast cloudiness during this period. In addition, we have not the data in December 2007-February 2008 due to calibration of Zvenigorod CIMEL instrument at the NASA GSFC facility.

The spectral dependence of the AOT average difference between Moscow and Zvenigorod is shown in Fig. 3. One can see the existence of a quite noticeable maximum at 380$440 \mathrm{~nm}$, which can be attributed to the additional effects of higher $\mathrm{NO}_{2}$ content in Moscow (Chubarova et al., 2009a), which possibly is not fully accounted for in the AERONET dataset (see a similar shape in $\mathrm{NO}_{2}$ absorption coefficients in Fig. 3). This difference can correspond to an additional $\mathrm{NO}_{2}$ content of about $0.3 \mathrm{DU}$ in Moscow and can be seen 
Table 1. Mean values of aerosol parameters in Moscow and the statistics of the differences $d P=P_{\text {Moscow }}-P_{\text {Zvenigorod }}$ between Moscow and Zvenigorod main aerosol parameters in different seasons. 2006-2009 period. Dataset 1.

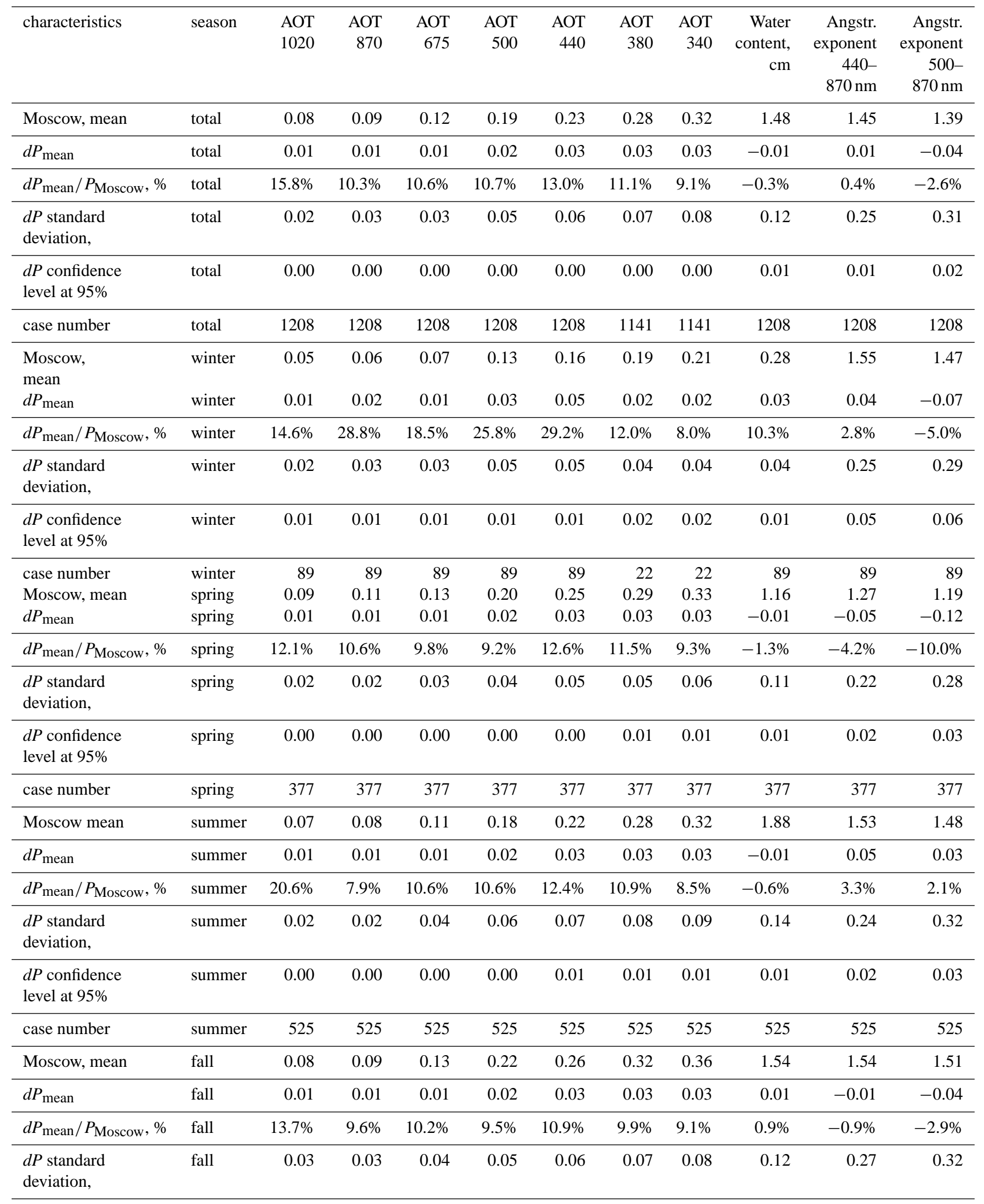


Table 1. Continued.

\begin{tabular}{|c|c|c|c|c|c|c|c|c|c|c|c|}
\hline characteristics & season & $\begin{array}{l}\text { AOT } \\
1020\end{array}$ & $\begin{array}{r}\text { AOT } \\
870\end{array}$ & $\begin{array}{r}\text { AOT } \\
675\end{array}$ & $\begin{array}{r}\text { AOT } \\
500\end{array}$ & $\begin{array}{r}\text { AOT } \\
440\end{array}$ & $\begin{array}{r}\text { AOT } \\
380\end{array}$ & $\begin{array}{r}\text { AOT } \\
340\end{array}$ & $\begin{array}{r}\text { Water } \\
\text { content, } \\
\mathrm{cm}\end{array}$ & $\begin{array}{r}\text { Angstr. } \\
\text { exponent } \\
440- \\
870 \mathrm{~nm}\end{array}$ & $\begin{array}{r}\text { Angstr. } \\
\text { exponent } \\
500 \\
870 \mathrm{~nm}\end{array}$ \\
\hline $\begin{array}{l}d P \text { confidence } \\
\text { level at } 95 \%\end{array}$ & fall & 0.00 & 0.00 & 0.00 & 0.01 & 0.01 & 0.01 & 0.01 & 0.02 & 0.04 & 0.04 \\
\hline case number & fall & 217 & 217 & 217 & 217 & 217 & 217 & 217 & 217 & 217 & 217 \\
\hline
\end{tabular}

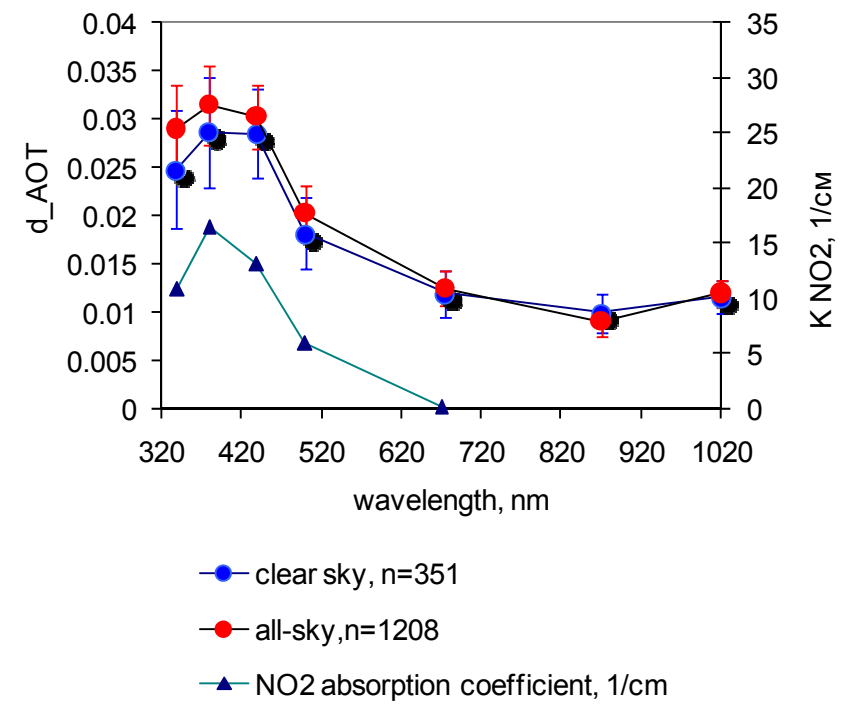

Fig. 3. Spectral dependence of the mean difference in AOT (dAOT) between Moscow and Zvenigorod (left axis) and $\mathrm{NO}_{2}$ absorption coefficients $\left(K_{\mathrm{NO}_{2}}\right)$ in CIMEL channels (right axis). The spectral dependence of dAOT obtained in clear sky conditions is shown in blue $(n=351)$; in all-sky conditions - in red color $(n=1208)$.

both in clear sky and all-sky conditions. We should mention that the standard AERONET version 2 algorithm uses the SCIAMACHY $\mathrm{NO}_{2}$ climatology for the period 20032005 with a spatial resolution of $0.25^{\circ} \times 0.25^{\circ}$ for correcting $\mathrm{NO}_{2}$ content in the atmosphere (see http://aeronet.gsfc.nasa. gov/new_web/publications.html). According to this climatology, the mean difference in $\mathrm{NO}_{2}$ content between the sites is about $0.15 \mathrm{DU}$ ( or $0.4 \times 10^{16} \mathrm{~mol} \mathrm{~cm}^{-2}$ ). The analysis of the climatology of the direct $\mathrm{NO}_{2}$ measurements by spectral instruments have shown much higher difference of 0.3-0.5 DU (Elokhov and Gruzdev, 1998; Gruzdev and Elokhov, 2010; Ivanov et al., 2010) which corresponds much better to our estimates.

The SCIAMACHY $\mathrm{NO}_{2}$ retrievals, which are used for $\mathrm{NO}_{2}$ correction in the AERONET algorithm, can be lower in Moscow, to some extent, due to comparatively large space averaging, which combines both clean and polluted areas.
The analysis of water vapor content $(W)$ shows no statistically significant difference between Moscow and Zvenigorod in clear sky and in all-sky conditions. However, according to Table 1, in winter period Moscow $W$ values are significantly higher $(d W=0.03 \mathrm{~cm}$ or $10 \%)$. The higher water content in Moscow during winter conditions can be explained by significantly higher temperatures in Moscow compared with Zvenigorod due to the megacity heating effect, which, in turn, corresponds to the higher water vapor content in the low troposphere. In spring and summer conditions, the difference in $W$ is not statistically significant both in clear-sky and in all-sky conditions.

There are very interesting tendencies in the spatial changes of the Angstrom exponent evaluated within the standard spectral interval $440-870 \mathrm{~nm}$. On average, there is a statistically significant correlation between the Angstrom exponent values observed in Moscow and Zvenigorod, though the correlation coefficient is lower $(r=0.65)$ than that obtained for aerosol optical thickness $(r=0.91)$. The correlation between the Angstrom exponent values together with high correlation between the AOT's can mean that for Moscow conditions the natural processes are likely the dominating factor in transformation of the aerosol particle size distribution. The application of another spectral range $(500-870 \mathrm{~nm})$ for evaluating the Angstrom exponent to eliminate the effects of possible $\mathrm{NO}_{2}$ contamination of AOT at $440 \mathrm{~nm}$ shows similar results.

The most pronounced, though small difference in Angstrom exponent values is observed in spring, when in Moscow they are smaller (about -0.05), and in summer, when they are higher (up to +0.05) than those in Zvenigorod. In spring, this happens, possibly, due to accumulation of coarse particles during winter, which, for example, are used for snow removal at highways, roads, and pavements, and after seasonal snow melting they can ascend up to the air, increasing the coarse mode particle concentration and, hence, decreasing Angstrom exponent. In the summer and in the fall, a small prevalence in fine aerosol mode can be attributed to generating the secondary fine mode aerosol due to additional pollution megacity effects.

Since there can be significant positive and negative deviations in AOT and Angstrom exponent between the "clean" and the "polluted" site (see Fig. 2, for example), we analyzed 

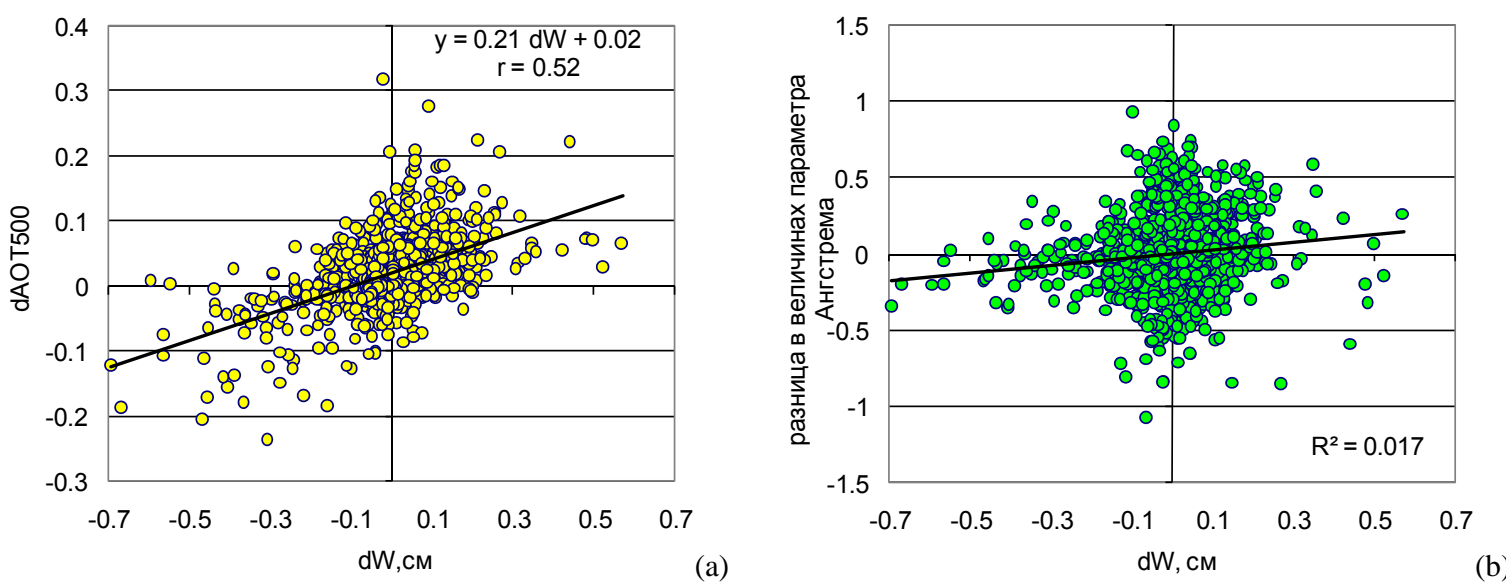

Fig. 4. Correlation between the Moscow-Zvenigorod differences in water vapor $d W$ and aerosol optical thickness $d$ AOT500 (a), and between differences in water vapor and Angstrom exponent (b). All - sky conditions.

the correlation between the simultaneously observed differences in water vapor content and the differences in aerosol optical thickness at these sites. It should be emphasized that water vapor content is an important characteristic of the air mass, therefore we can distinguish the cases of its possible influence on aerosol variability. The results are presented in Fig. 4. One can see a statistically significant correlation between both differences in $\mathrm{W}$ and in AOT. This means that the spatial difference in $W$, which is an indicator of the various air masses at the sites, is the reason of the different AOT values there. For example, during the Arctic air advection from north-eastern region one can obtain both smaller AOT and $W$ values, first in Moscow and then in Zvenigorod. In case of south-western air mass advection, higher AOT and $W$ are observed in Zvenigorod first and then in Moscow. The time lag existence between the advection of the same air mass at the two sites leads sometimes to a significant effects of about $|d \mathrm{AOT}|=0.2-0.3$. Thus, the existing correlation, shown in Fig. 4a confirms that large changes in AOT between Moscow and Zvenigorod often take place due to the non simultaneous air mass advection at the sites even at the distance of $55 \mathrm{~km}$ !

In order to account for the possible effects of the temporal lag in AOT the correction to the AOT's was applied using the obtained linear regression equation between $d$ AOT500 and $d W$ :

$d$ AOT500 $=0.21 d W+0.02, \quad r=0.52$

Figure 5 presents frequency distribution of the initial $d$ AOT500 dataset and the dataset corrected on the air transport temporal lag. As a result, we obtained an increase in the occurrence of positive $d$ AOT (more than $75 \%$ of cases compared with the $72 \%$ calculated using the initial dataset), the decrease in $d$ AOT standard deviation from 0.05 to 0.04 , and the same average difference of about 0.02 . It is clearly seen that the removal of this factor does not change significantly the mean results but it certainly leads to even more

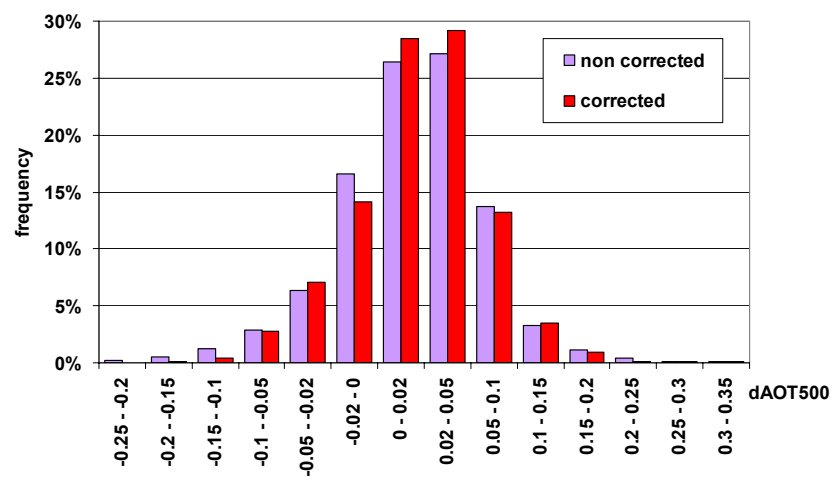

Fig. 5. Frequency distribution of difference in AOT500 with the correction on the air transport lag and without it.

pronounced aerosol pollution effects with smaller number of negative $d$ AOT cases.

Figure $4 \mathrm{~b}$ illustrates the corresponding relation between the differences in Angstrom exponent and water vapor content. Contrary to AOT, no dependence can be seen. The analysis of the differences between $d \mathrm{AOT}$ and the differences in Angstrom exponent between the sites also revealed the absence of any statistically significant correlation.

In order to analyze spatial distribution of aerosol optical thickness over the whole Moscow region and nearby territories we used $1^{\circ} \times 1^{\circ}$ MODIS data, averaged for the same 2006-2009 period (Remer et al., 2008). There is a good agreement between the mean difference in AOT obtained from the AERONET and MODIS data over the considered sites, which is about 0.02 and 0.03 at $\lambda=500 \mathrm{~nm}$. This confirms a satisfactory quality of the mean MODIS aerosol retrievals.

Figure 6 shows a spatial distribution of difference between AOT550 over Moscow and the nearby area $\left(D=\mathrm{AOT}_{\text {Moscow }}-\mathrm{AOT}_{\varphi, \lambda}\right)$ obtained from the MODIS 


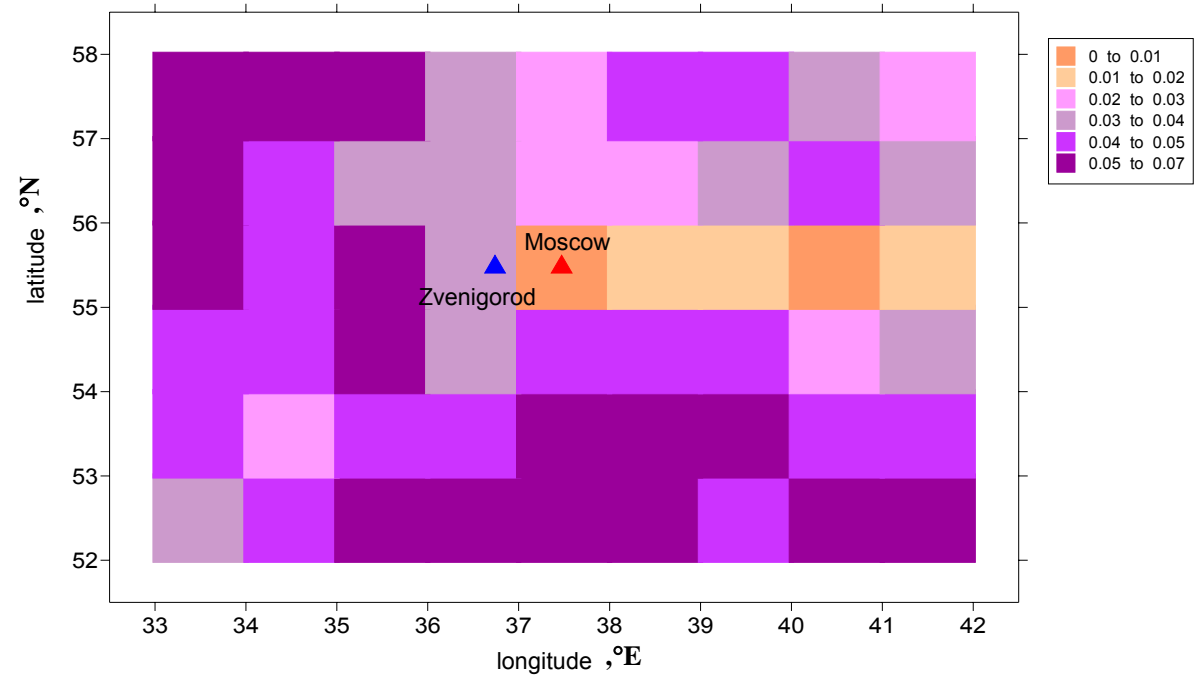

Fig. 6. Average difference in AOT550 over Moscow region and nearby territory. MODIS data, collection 5.

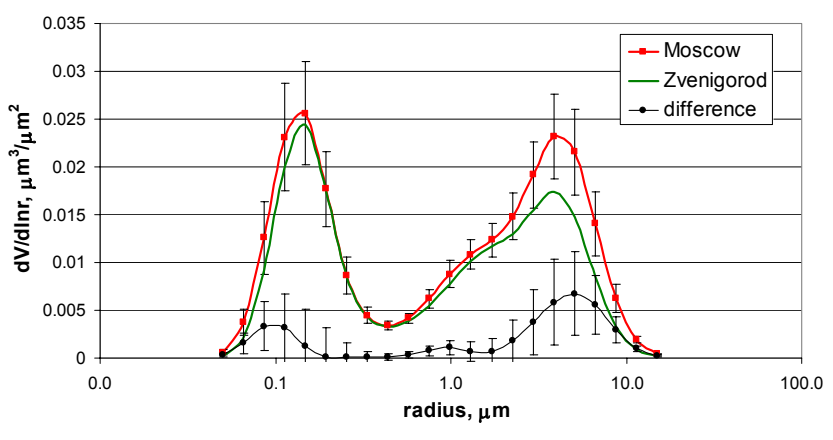

Fig. 7. Mean aerosol volume size distribution $d V / d \ln r$ in Moscow and the difference in $d V / d \ln r$ between Moscow and Zvenigorod. $n=112$.

collection 5 data. One can see that the highest AOT values of the same level are observed directly over Moscow megacity as well as over the spot to the east of Moscow due to the effects of forest and peatbog fires, which usually take place in this area. Due to prevailing westerlies, there is a bias to higher AOT's to the east of Moscow as the effect of the pollution, while the nearest clean area to Moscow is located directly to the west from Moscow. The cleanest background areas are located at the distance of more than $150 \mathrm{~km}$ to the west and to the south with the $d$ AOT550 $~ 0.05-0.07$. Hence, one can speak about the difference of $d$ AOT550 $>0.05$ as the difference with the background aerosol conditions over this continental zone in the absence of pollution effects.

The statistic characteristics for the differences in some optical and radiative aerosol properties are shown in Table 2. They have been calculated on the base of the Dataset 2 .
A comparison between the mean aerosol size distributions over Moscow and over Zvenigorod shows a considerably higher concentration of coarse mode particles in Moscow, especially, near radius of $5 \mu \mathrm{m}$ (about $31 \%$ ) that is much higher than the uncertainty of measurements (Fig. 7). Also a higher concentration of fine mode particles near $0.1 \mu \mathrm{m}$ is observed. The difference in fine mode concentration should be studied further, because of possible $\mathrm{NO}_{2}$ contamination in Moscow, as discussed above, which can be attributed to an artificial increase in fine mode particles.

There is a pronounced correlation between Moscow and Zvenigorod effective radii for different aerosol modes at approximately the same level of determination coefficients $\left(r^{2}>0.4\right)$ for fine, coarse and total effective radii $R_{\text {eff }}$ that means simultaneous changes in all aerosol fractions. However, the analysis of changes in $R_{\text {eff }}$ as a function of $d W$ has not revealed any dependence. No dependence has been also obtained between the absolute values of effective radii and water vapor content at both sites. Aerosol single scattering albedo, as well as asymmetry factor of the aerosol phase function, are the important retrieval products of the AERONET, since they are used as input parameters in RT modelling. Figure 8 presents the mean asymmetry factor $g$ for various aerosol modes in Moscow and its difference with Zvenigorod data. Due to the described differences in aerosol size distribution, variations of asymmetry factor between Moscow and Zvenigorod for fine and coarse modes are very pronounced especially in visible spectral region.

Since the inversion method requires the threshold of AOT440 > 0.4 and typical AOT's in Moscow are relatively low (mean AOT440 0.23), there are only few cases in SSA retrievals. It is necessary to mention that this is a quite typical situation for high latitude boreal zone. Over these areas relatively high AOT values are observed mainly in smoke 

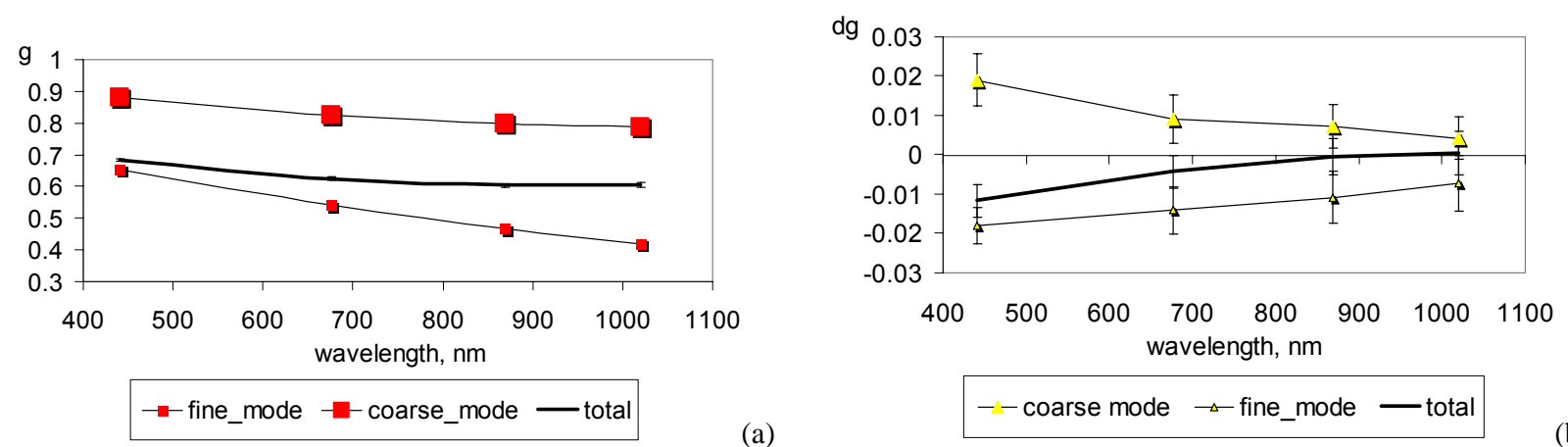

Fig. 8. Mean asymmetry factor $(g)$ in Moscow for various aerosol modes (a) and the difference in mean asymmetry factor $(d g)$ between Moscow and Zvenigorod (b).
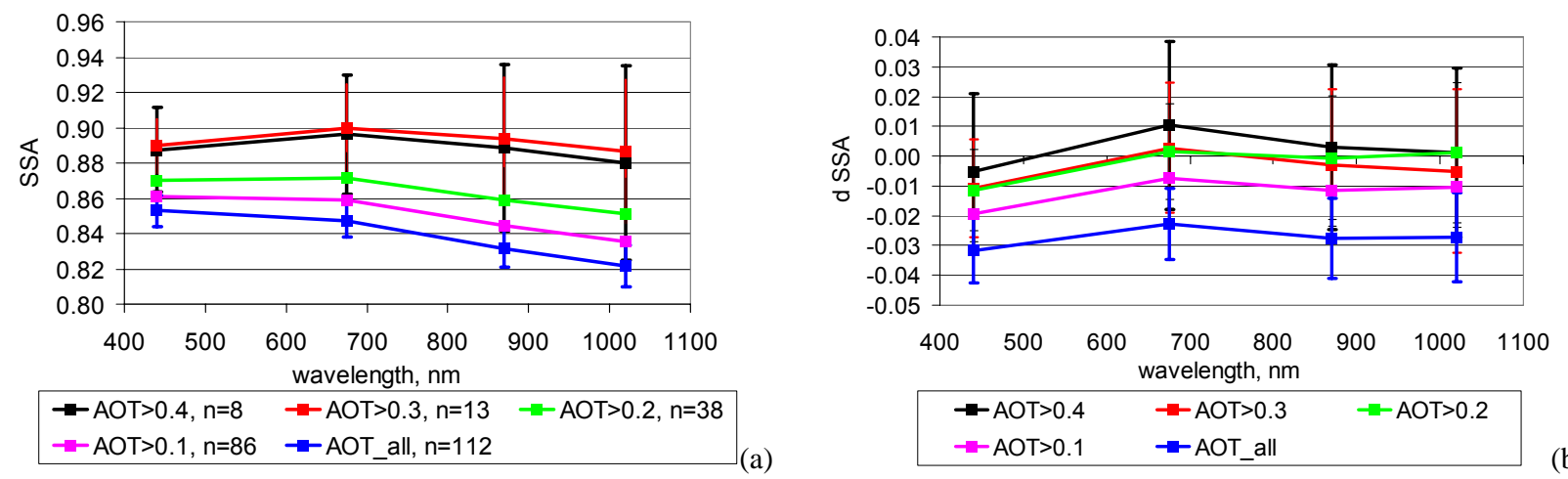

(b)

Fig. 9. Single scattering albedo (SSA) as a function of wavelength at different AOT thresholds in Moscow (a) and the SSA difference ( $d$ SSA) between Moscow and Zvenigorod (b).

aerosol conditions. Therefore, in addition, we used other thresholds (AOT $>0.3$, AOT $>0.2$, AOT $>0.1)$ and all AOT statistics to analyze SSA for larger number of cases at different aerosol loading. The mean SSA in Moscow and its difference with Zvenigorod at different AOT thresholds are shown in Fig. 9 and in Table 2. One can see the absence of the difference in SSA between Moscow and Zvenigorod at large AOT $>0.4$. At the same time there is a tendency of SSA decreasing in Moscow with AOT decrease. The difference can reach $d \mathrm{SSA}=-0.03$ when considering all available measurements of the Dataset 2 (see Table 2). However, even this difference is equal to the uncertainty of the SSA retrievals, while SSA retrievals at AOT440 $<0.4$ have even the larger uncertainty of measurements (Dubovik et al., 2000). Taking this into consideration, the obtained difference can be considered only as a preliminary result. More pronounced difference in SSA at $440 \mathrm{~nm}$ can be explained by some effects of the $\mathrm{NO}_{2}$, which has large absorption coefficient near this wavelength and the additional $\mathrm{NO}_{2}$ content in the atmosphere of large Moscow megalopolis (see Fig. 3).

Aerosol radiative forcing (ARF) at the top of the atmosphere (TOA) is used for characterizing the impact of aerosol on the temperature regime. Since the standard AERONET radiation products include the calculation of ARF (Garcia et al., 2008), we used this characteristic to estimate the influence of the large city on its changes. The AERONET aerosol radiative forcing is defined as the difference between the global solar irradiance with and without aerosol at the top and at the bottom of the atmosphere:

$$
\begin{aligned}
& \mathrm{ARF}_{\mathrm{TOA}}=-\left(F_{\mathrm{TOA}}^{\uparrow \mathrm{a}}-F_{\mathrm{TOA}}^{\uparrow \mathrm{o}}\right) \\
& \mathrm{ARF}_{\mathrm{BOA}}=\left(F_{\mathrm{BOA}}^{\downarrow \mathrm{a}}-F_{\mathrm{BOA}}^{\downarrow \mathrm{o}}\right),
\end{aligned}
$$

where $F^{\mathrm{a}}$ and $F^{\mathrm{o}}$ are the broadband fluxes at the top (TOA) and at the bottom (BOA) of the atmosphere with and without aerosols. Usually net fluxes are used in the ARF analysis (see, e.g. Yu et al., 2006). However, when we speak about the ARF differences obtained by the AERONET algorithm at the top of the atmosphere between the two sites, the resulting value will be the same as if considering the net fluxes. According to the statistics shown in Table 2, mean ARF at the top of the atmosphere is about $-0.9 \pm 0.6 \mathrm{~W} \mathrm{~m}^{-2}$. This means that the average radiative effect of the urban aerosol is characterized by an increase in upwelling radiation leading to the negative difference in ARF at the TOA and, as a result, cooling the troposphere. This happens due to prevailing higher content of slightly absorbing aerosol in Moscow. The 
Table 2. Main statistics for the mean differences in aerosol and radiative characteristics between Moscow and Zvenigorod. Dataset 2.

\begin{tabular}{|c|c|c|c|c|c|c|}
\hline & average & $\sigma$ & $n$ & $\min$ & $\max$ & confidence level \\
\hline AOT_1020 & 0.012 & 0.017 & 112 & -0.037 & 0.069 & 0.003 \\
\hline AOT_870 & 0.012 & 0.019 & 112 & -0.040 & 0.072 & 0.004 \\
\hline AOT_675 & 0.014 & 0.025 & 112 & -0.050 & 0.092 & 0.005 \\
\hline AOT_500 & 0.020 & 0.041 & 112 & -0.125 & 0.146 & 0.008 \\
\hline AOT_440 & 0.030 & 0.051 & 112 & -0.160 & 0.190 & 0.009 \\
\hline AOT_380 & 0.035 & 0.062 & 112 & -0.209 & 0.228 & 0.011 \\
\hline AOT_340 & 0.032 & 0.069 & 112 & -0.259 & 0.248 & 0.013 \\
\hline Water(W, cm) & -0.040 & 0.141 & 112 & -0.688 & 0.290 & 0.026 \\
\hline $\begin{array}{l}\text { Angstrom exponent at } \\
440-870 \mathrm{~nm}\end{array}$ & -0.029 & 0.120 & 112 & -0.416 & 0.403 & 0.022 \\
\hline $\begin{array}{l}\text { Asymmetry factor at } \\
440 \mathrm{~nm} \text { (Total) }\end{array}$ & -0.012 & 0.022 & 112 & -0.078 & 0.034 & 0.004 \\
\hline $\begin{array}{l}\text { Asymmetry factor at } \\
675 \mathrm{~nm} \text { (Total) }\end{array}$ & -0.004 & 0.023 & 112 & -0.123 & 0.047 & 0.004 \\
\hline $\begin{array}{l}\text { Asymmetry factor at } \\
870 \mathrm{~nm} \text { (Total) }\end{array}$ & 0.000 & 0.026 & 112 & -0.140 & 0.051 & 0.005 \\
\hline $\begin{array}{l}\text { Asymmetry factor at } \\
1020 \mathrm{~nm} \text { (Total) }\end{array}$ & 0.000 & 0.030 & 112 & -0.153 & 0.054 & 0.006 \\
\hline SSA440-Total* & $-0.032(-0.05)$ & $0.058(0.04)$ & $112(8)$ & $-0.218(-0.06)$ & $0.078(0.08)$ & $0.011(0.03)$ \\
\hline SSA675-Total* & $-0.023(0.01))$ & $0.063(0.04)$ & $112(8)$ & $-0.238(-0.03)$ & $0.145(0.10)$ & $0.012(0.04)$ \\
\hline SSA870-Total ${ }^{*}$ & $-0.028(0.03)$ & $0.072(0.04)$ & $112(8)$ & $-0.258(-0.04)$ & $0.221(0.09)$ & $0.014(0.04)$ \\
\hline SSA1020-Total* & $-0.027(0.00)$ & $0.080(0.04)$ & $112(8)$ & $-0.279(-0.05)$ & $0.269(0.08)$ & $0.015(0.04)$ \\
\hline RadiativeForcing(BOA)** & -6.67 & 10.61 & 92 & -44.51 & 27.06 & 2.17 \\
\hline RadiativeForcing(TOA) ${ }^{* *}$ & -0.88 & 2.81 & 92 & -8.37 & 6.16 & 0.58 \\
\hline ForcingEfficiency(BOA)** & -18.96 & 43.81 & 92 & -175.87 & 102.19 & 8.95 \\
\hline ForcingEfficiency(TOA)** & 6.15 & 25.09 & 92 & -50.94 & 72.13 & 5.13 \\
\hline $\begin{array}{l}\text { Volume Concentration - } \\
\text { Total }\end{array}$ & 0.000 & 0.030 & 112 & -0.153 & 0.054 & 0.006 \\
\hline Effective Radius - Total & -0.018 & 0.025 & 112 & -0.096 & 0.041 & 0.005 \\
\hline Effective Radius - Fine & -0.007 & 0.013 & 112 & -0.042 & 0.026 & 0.002 \\
\hline Effective Radius - Coarse & 0.171 & 0.340 & 112 & -0.988 & 1.187 & 0.063 \\
\hline
\end{tabular}

* - case number in the brackets is given for the cases with the standard threshold (AOT440 > 0.4) for single scattering albedo.

$*$ - case number for calculation of the difference in aerosol radiative forcing has an additional restriction on the difference in solar zenith angle of $\pm 0.02^{\circ}$.

negative difference in $\mathrm{ARF}_{\mathrm{TOA}}$ increases with the increase of the AOT difference between Moscow and Zvenigorod of up to $-4 \mathrm{~W} \mathrm{~m}^{-2}$ according to the linear trend (Fig. 10). However, if a possible lower single scattering albedo for Moscow is taken into account (see the discussion above), the total effect in cooling the atmosphere is less than should have been if the SSA values were the same. The cases with the positive ARF difference mainly correspond to the situations with higher AOT values in Zvenigorod.

In addition, we estimated photosynthetically active radiation (PAR) and UV irradiance at ground both for Moscow and Zvenigorod aerosol clear sky conditions using the TUV RT model with 8 stream DISORT solver (Madronich and Flocke, 1998), which has been slightly modified to account for the available input parameters (Chubarova, 2004). The results are presented in Table 3. On average, there is a small relative decrease in solar irradiance at ground of about
2.3-3.4\% depending on wavelength with a slightly higher attenuation in UV spectral range (up to $3.4 \%$ for UV-A) and smaller in visible, mainly, due to the increase in total optical thickness at shorter wavelengths and, hence, in dAOT. However, a minimum relative difference can be higher than $20 \%$ or $10 \%$ respectively for UV and visible spectral range in conditions when $d$ AOT's were higher than 0.1 .

\section{Discussion}

The analysis of long-term simultaneous AERONET CIMEL aerosol observations in Moscow and Moscow suburbs (Zvenigorod) has shown statistically significant higher AOT500 values in Moscow megacity with the average difference of about 0.02. There is a high correlation in the AOT's, in the Angstrom exponent values, in the effective radii and 
Table 3. Absolute and relative differences in ultraviolet and visible (PAR) irradiance reaching the surface due to the changes in aerosol properties in Moscow megacity. Clear sky conditions. $X=350 \mathrm{DU}$.

\begin{tabular}{lrrrrr}
\hline & UV & $\begin{array}{r}\text { UV-B } \\
\text { 280-400 nm }\end{array}$ & $\begin{array}{r}\text { UV-A } \\
280-315 \mathrm{~nm}\end{array}$ & UV_index & $\begin{array}{r}\text { PAR } \\
\text { 315-400 nm }\end{array}$ \\
\hline Absolute difference $\mathrm{W} \mathrm{m}^{-2}$ & -0.65 & -0.01 & -0.64 & -0.04 & -3.60 \\
Relative difference, \% & $-3.4 \%$ & $-3.1 \%$ & $-3.4 \%$ & $-3.2 \%$ & $-2.3 \%$ \\
Mininum relative difference, \% & $-22.2 \%$ & $-21.0 \%$ & $-22.2 \%$ & $-21.3 \%$ & $-13.4 \%$ \\
Maximum relative difference, \% & $6.8 \%$ & $6.9 \%$ & $6.8 \%$ & $6.8 \%$ & $6.5 \%$ \\
\hline
\end{tabular}

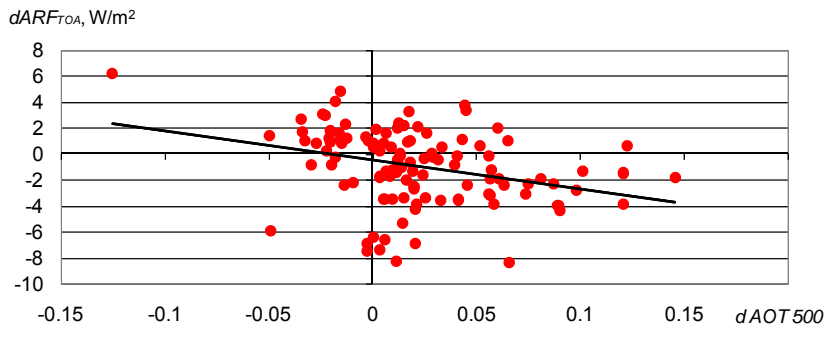

Fig. 10. Dependence of the difference in aerosol radiative forcing at TOA $\left(d \mathrm{ARF}_{\mathrm{TOA}}\right)$ between Moscow and Zvenigorod as a function of $d$ AOT500.

in water vapor content between the sites. This confirms that natural processes are the dominating factor in the changes of the aerosol properties even over the large megacity like Moscow. During winter season, the most pronounced positive difference is observed for AOT values comprising +0.03 (or $26 \%$ ) and water vapor content $(d W=+0.03 \mathrm{~cm})$. Winter period is also characterized by the lowest correlation in the AOT's $(r=0.8)$ and water vapor content $(r=0.85)$. These features prove that in winter the megacity pollution is the most noticeable, though the absolute values of AOT have a seasonal minimum. It should be noted that due to the meteorological conditions, the number of measurements in winter are less than in other seasons. So the conclusions, based on the statistical analysis of winter data, are less reliable than in other seasons. Some interesting features in aerosol properties are observed in other seasons: in spring a significantly lower Angstrom exponent is observed in Moscow, and in summer and in fall they are notably higher. The data analysis has revealed a specific spectral dependence of the AOT difference with the maximum difference at $440 \mathrm{~nm}$. The shape of the dependence is similar to the shape of $\mathrm{NO}_{2}$ absorption coefficients and since Moscow conditions are characterized by a large $\mathrm{NO}_{2}$ content, it may not be fully accounted by the SCIAMACHY data correction. This effect should be studied further to determine whether this is a real aerosol feature or the result of the additional $\mathrm{NO}_{2}$ contamination. As a result, some retrieved aerosol radiative characteristics (for example, single scattering albedo and asymmetry factor at $440 \mathrm{~nm}$ ) should be considered with caution. Since water vapor content is one of the most important characteristics of the air mass, the application of the data on water vapor content allows us to reveal the cause of the nature of the AOT difference. The positive correlation between $d$ AOT and $d W$ has been found, which explains many cases with large differences in AOT by the temporal lag in the air transport from Moscow to Zvenigorod or vice versa. The application of the AOT correction on temporal lag using the linear regression equation between $d$ AOT500 and $d W$ has led to a small increase in the occurrence of positive $d \mathrm{AOT}$, the decrease in $d \mathrm{AOT}$ standard deviation from 0.05 to 0.04 , and the same average difference of about 0.02. Hence, the removal of this factor does not change significantly the mean results but it certainly leads to even more pronounced aerosol pollution effects with smaller number of negative $d$ AOT cases.

By using the satellite MODIS data over the same period of observations as for ground-based measurements, the spatial aerosol distribution has been estimated around Moscow and nearby territories. There is an agreement between ground-based and satellite average AOT550 difference over Moscow and Zvenigorod, which proves a satisfactory quality of MODIS data. The spatial AOT distribution is characterized by a bias with higher AOT's in Moscow and downwind at about $200 \mathrm{~km}$ to the east. The second maximum is generated due to gas-aerosol emission from forest and peatbog fires. The cleanest background conditions with the AOT difference with respect to Moscow of more than 0.05 are located at the distance of more than $150 \mathrm{~km}$ to the west and to the south from Moscow, that is 3 times farther than the Zvenigorod location.

The difference in single scattering albedo between the sites is not statistically significant for the AOT440 $>0.4$ at $440 \mathrm{~nm}$, but the number of cases is very small $(n=8)$. Due to lack statistics SSA spectral dependence at high AOT440 differs from the previously obtained dependence, which was characterized by smooth SSA reduction with wavelength (Chubarova et al., 2009b). There is a tendency of SSA decrease in Moscow at lower AOT values. However, the obtained SSA retrievals at smaller AOT have larger uncertainty of SSA evaluation than typical uncertainty of 0.03 (Dubovik et al., 2000). Therefore, the obtained difference can be considered only as a preliminary result. 
More pronounced difference in SSA at $440 \mathrm{~nm}$ can be explained by some effects of the $\mathrm{NO}_{2}$ additional absorption in the atmosphere of large Moscow megalopolis. There are the large $\mathrm{NO}_{2}$ absorption coefficients near this wavelength (see Fig. 3). The aerosol phase function asymmetry factor has also some differences due to the changes in aerosol size distribution, which is biased to its right and left ends (see Fig. 7). As a result, the asymmetry factor is higher for coarse aerosol mode and lower for the fine aerosol mode. All these aerosol characteristics allow one to estimate the irradiances and radiative forcing at ground level and at the top of the atmosphere. The difference in ARF at the TOA between the "polluted" and "clean" sites is negative that corresponds to an increase in upwelling radiation and, as a result, cooling the troposphere with average effect of $d \mathrm{ARF}_{\mathrm{TOA}}=-0.9 \pm 0.6 \mathrm{~W} \mathrm{~m}^{-2}$. This is explained mainly by higher AOT and only slightly lower SSA values in Moscow compared with Zvenigorod conditions. The relative difference in solar radiation reaching the ground between the sites on average comprises about $-2-3 \%$ with a slight decrease in visible spectral range. However, in some situations the attenuation can reach $-13 \%$ in visible and more than $-20 \%$ in UV spectral region.

\section{Conclusions}

According to the continuous simultaneous measurements with the use of high-quality AERONET CIMEL sun/sky photometers the average effect of aerosol pollution has been estimated to be about $d$ AOT $=0.02$ in visible spectral region. The most pronounced difference is observed in winter conditions when the relative AOT difference can reach $26 \%$. According to the satellite data (which agree well with our ground-based measurements) the cleanest background conditions (with the $d$ AOT550 $>0.05$ ) are located at the distance of more than $150 \mathrm{~km}$ to the west and the south from Moscow, that is 3 times farther than the Zvenigorod location.

The high correlation of the AOT's, the Angstrom exponent values, and the effective radii between the sites confirms that natural process are the dominating factor in the changes of the aerosol properties in Moscow and Moscow suburb. The existence of positive correlation between dAOT and $d W$ explains the cases with large differences in AOT by the time lag in the air mass transport between the sites. However, after excluding the difference due to this factor, AOT in Moscow remains higher in more than $75 \%$ cases with the same mean $d$ AOT and smaller standard deviation.

The mean aerosol asymmetry factor in Moscow is higher for coarse aerosol mode and lower for the fine aerosol mode. The difference in single scattering albedo between the sites is not statistically significant at the AOT440 $>0.4$, though there is a tendency of SSA decrease in Moscow compared with Zvenigorod at lower AOT.
The difference in radiative forcing at the TOA due to aerosol pollution effects is negative that corresponds to an increase in upwelling radiation and cooling the troposphere with average $d \mathrm{ARF}_{\mathrm{TOA}}=-0.9 \mathrm{~W} \mathrm{~m}^{-2}$. This is explained by the higher AOT values and only slightly lower SSA in Moscow compared with Zvenigorod conditions.

Due to the aerosol pollution effects the PAR and UV irradiance reaching the ground is only $-2-3 \%$ less in Moscow, though in some situations the attenuation can reach $-13 \%$ in visible and more than $-20 \%$ in UV spectral region.

Acknowledgements. The work was partially supported by the Ministry of education and science of the Russian Federation (contract \#02.740.11.0676), and by the RFBR grants \#10-05-01019, \#09-05-00582.

Edited by: A. Kokhanovsky

\section{References}

Afifi, A. A. and Azen, S. P.: Statistical Analysis, A Computer Oriented Approach, 2nd edition, Academic, San Diego, California, 486 pp., 1979.

Chubarova, N. E.: Influence of Aerosol and Atmospheric Gases on Ultraviolet Radiation in Different Optical Conditions Including Smoky Mist of 2002, Dokl. Earth Sci., 394(1), 62-67, 2004.

Chubarova, N. Y., Larin, I. K., Lebedev, V. V., Partola, V. S., Lezina, Ye. A., and Rublev, A. N.: Experimental and model study of changes in spectral solar irradiance in the atmosphere of large city due to tropospheric $\mathrm{NO}_{2}$ content, in: Current Problems In Atmospheric Radiation (IRS 2008) Proceedings of the International Radiation Symposium (IRC/IAMAS) Foz do Iguasu, Brazil, 3-8 August 2008, edited by: Nakajima, T. and Yamasoe, M. A., AIP Conference Proceedings, Melville, New York, 1100, 459-462, 2009a.

Chubarova, N. Y., Prilepsky, N. G., Rublev, A. N., and Riebau, A. R.: A Mega-Fire event in central Russia: fire weather, radiative, and optical properties of the atmosphere, and consequences for subboreal forest plants, in: Developments in Environmental Science, Volume 8, edited by: Bytnerowicz, A., Arbaugh, M., Riebau, A., and Andersen, C., Elsevier B. V., 249-267, 2009 b.

Chubarova, N. Y.: Seasonal distribution of aerosol properties over Europe and their impact on UV irradiance, Atmos. Meas. Tech., 2, 593-608, doi:10.5194/amt-2-593-2009, 2009.

Dubovik, O. and King, M. D.: A flexible inversion algorithm for retrieval of aerosol optical properties from Sun and sky radiance measurements, J. Geophys. Res., 105(D16), 20673-20696, 2000.

Dubovik, O., Smirnov, A., Holben, B. N., King, M. D., Kaufman, Y. J., Eck, T. F., and Slutsker, I.: Accuracy assessments of aerosol optical properties retrieved from Aerosol Robotic Network (AERONET) Sun and sky radiance measurements, J. Geophys. Res., 105(D8), 9791-9806, 2000.

Dubovik, O., Holben, B. N., Eck, T. F., Smirnov, A., Kaufman, Y. J., King, M. D., Tanre, D., and Slutsker. I.: Variability of absorption and optical properties of key aerosol types observed in worldwide locations, J. Atmos. Sci., 59, 590-608, 2002. 
Eck, T. F., Holben, B. N., Reid, J. S., Dubovik, O., Smirnov, A., O'Neill, N. T., Slutsker, I., and Kinne, S.: Wavelength dependence of the optical depth of biomass burning, urban and desert dust aerosols, J. Geophys. Res., 104(D24), 31333-31349, 1999.

Elokhov, A. S. and Gruzdev, A. N.: Measurements of column contents and vertica distribution of $\mathrm{NO}_{2}$ at Zvenigorod Scientific Station, Proc. SPIE, 3583, 547-554, 1998.

Garcia, O. E., Diaz, A. M., Exposito, F. J., Diaz, J. P., Dubovik, O., Dubuisson, P., Roger, J.-C., Eck, T. F., Sinyuk, A., Derimian, Y., Dutton, E. G., Schafer, J. S., and Holben, B. N.: Validation of AERONET estimates of atmospheric solar fluxes and aerosol radiative forcing by ground-based broadband measurements, J. Geophys. Res., 113, D21207, doi:10.1029/2008JD010211, 2008.

Gorbarenko, E. V.: Spatial and temporal variability of the atmospheric aerosol optical thickness on the territory of former USSR, in: IRS'96 Current problems in Atmospheric Radiation, edited by: Smith, W. L. and Stamnes, K., Deepak Publishing, Hampton, Virginia, USA, 774-777, 1997.

Gorbarenko, E. V., Yerokhina, E., Lukin, A. B.: Long-period changes in aerosol optical thickness of the atmosphere in Russia, Russ. Meteorol. Hydrol., 7, 25-31, 2006.

Gruzdev, A. N. and Elokhov, A. S.: Validation of Ozone Monitoring Instrument $\mathrm{NO}_{2}$ measurements using ground based $\mathrm{NO}_{2}$ measurements at Zvenigorod, Russia, Int. J. Remote Sens., 31(2), 497-511, 2010.

Holben, B. N., Eck, T. F., Slutsker, I., Tanre, D., Buis, J. P., Setzer, A., Vermote, E., Reagan, J. A., Kaufman, Y. J., Nakajima, T., Lavenu, F., Jankowiak, I., and Smirnov, A.: AERONET - A federated instrument network and data archive for aerosol characterization, Remote Sens. Environ., 66, 1-16, 1998.

IPCC Climate Change 2007: The Physical Science Basis, Contribution of Working Group I to the Fourth Assessment Report of the Intergovernmental Panel on Climate Change, edited by: Solomon, S., Qin, D., Manning, M., Chen, Z., Marquis, M., Averyt, K. B., Tignor, M., and Miller, H. L., Cambridge University Press, Cambridge, UK and New York, NY, USA, 2007.

Ivanov, V. A., Elokhov, A. S., Postylyakov, O. V., and Belikov, I. B.: Preliminary results of boundary layer nitrogen dioxide integral content in Moscow area, Curr. Prob. Remote Sens. Earth Sp., 7(1), 92-98, 2010.
Kazadzis, S., Bais, A., Amiridis, V., Balis, D., Meleti, C., Kouremeti, N., Zerefos, C. S., Rapsomanikis, S., Petrakakis, M., Kelesis, A., Tzoumaka, P., and Kelektsoglou, K.: Nine years of UV aerosol optical depth measurements at Thessaloniki, Greece, Atmos. Chem. Phys., 7, 2091-2101, doi:10.5194/acp-7-20912007, 2007.

Madronich, S. and Flocke, S.: The role of solar radiation in atmospheric chemistry, in: Handbook of environmental chemistry, Springer-Verlag, Heidelberg, 1-26, 1998.

Remer, L. A., Kleidman, R. G., Levy, R. C., Kaufman, Y. J., Tanré, D., Mattoo, S., Martins, J. V., Ichoku, C., Koren, I., Yu, H., and Holben, B. N.: Global aerosol climatology from the MODIS satellite sensors, J. Geophys. Res., 113, D14S07, doi:10.1029/2007JD009661, 2008.

Ruckstuhl, C., Philipona, R., Behrens, K., Coen, M., Dürr, B., Heimo, A., Mätzler, C., Nyeki, S., Ohmura, A., Vuilleumier, L., Weller, M., Wehrli, C., and Zelenka, A.: Aerosol and cloud effects on solar brightening and the recent rapid warming, Geophys. Res. Lett., 35, L12708, doi:10.1029/2008GL034228, 2008.

Smirnov, A., Holben, B. N., Eck, T. F., Dubovik, O., and Slutsker, I.: Cloud-screening and quality control algorithms for the AERONET database, Remote Sens. Environ., 73, 337-349, 2000.

Tarasova, T. A. and Yarkho, E. V.: Determination of aerosol optical thickness using measurements of direct integral solar radiation, Sov. Meteorol. Hydrol., Engl. Trans., 12, 66-71, 1991.

Uliumdzhieva, N., Chubarova, N., and Smirnov, A.: Aerosol characteristics of the atmosphere over Moscow from Cimel sun photometer data, Meteorol. Hydrol., 1, 48-57, 2005.

Yu, H., Kaufman, Y. J., Chin, M., Feingold, G., Remer, L. A., Anderson, T. L., Balkanski, Y., Bellouin, N., Boucher, O., Christopher, S., DeCola, P., Kahn, R., Koch, D., Loeb, N., Reddy, M. S., Schulz, M., Takemura, T., and Zhou, M.: A review of measurement-based assessments of the aerosol direct radiative effect and forcing, Atmos. Chem. Phys., 6, 613-666, doi:10.5194/acp-6-613-2006, 2006. 